\title{
Towards Human-Oriented Norms: Considering the Effects of Noise Exposure On Board Ships
}

\author{
Rafet Emek Kurt ${ }^{1}$, Hassan Khalid ${ }^{1}$, Osman Turan ${ }^{1}$, Mark Houben ${ }^{2}$, Jelte Bos ${ }^{2,3}$, Ismail Hakki \\ Helvacioglu $^{4}$ \\ ${ }^{1}$ Department of Naval Architecture, Ocean and Marine Engineering, University of Strathclyde, Glasgow, UK \\ ${ }^{2}$ TNO, Soesterberg, The Netherlands \\ ${ }^{3}$ Faculty of Behavioural and Movement Sciences, Vrije Universiteit, Amsterdam, The Netherlands \\ ${ }^{4}$ Faculty of Naval Architecture and Ocean Engineering, Istanbul Technical University, Istanbul, Turkey
}

\section{Abstract}

With modern trends of decrease in crew numbers on board ships together with increased operational demands and paperwork, crew fatigue and comfort have become more critical and are being given more importance. It is well known that environmental factors affect crew comfort and performance. The two outstanding factors which exist in the shipboard environment are vessel motions and noise. As such, the findings and lessons learnt from other industrial sectors are considered to be less relevant for ships. Therefore, it is necessary to conduct focused research to understand the effects of these factors, so that the lessons learnt can be integrated into the ship design process so as to mitigate their adverse effects during vessel operations. Due to obvious performance issues, ship motions and motion sickness research has attracted far more interest than human response to noise. This paper reports the findings of a recent research study undertaken as part of an EU FP7 research project, namely SILENV, which investigated the current levels of crew noise exposure through field studies. Furthermore, developed models on human response to noise on board ships and SILENV green label noise standards are also introduced in comparison with the current normative framework.

Keywords: Noise, Comfort, Ship, Noise Exposure, Crew, SILENV Project

\section{Introduction}

Today, as a result of technological developments, ships are equipped with sophisticated systems and automation. This has triggered a trend to decrease the number of crew members on board ships. Nevertheless, these automated systems still require human intervention for interpreting the information or when tasks require decision-making. Therefore, as compared to the past, even though the physical workload of the crew members on today's vessels decreased, the cognitive load is much higher than it used to be. As a result, maintaining the performance of the crew has become more important than before to achieve safe shipping operations. Investigations of the shipping accidents from US, UK, Canada, and Australia showed that human error is the major contributor of shipping accidents where 80 to $85 \%$ of all accidents were primarily caused by or associated with human error (Baker and Seah, 2004). As a result of this increased understanding on the importance of the human element, more research was focused on human factors on board ships.

12

Corresponding Author: Rafet Emek Kurt

Tel: +44 (0)141548 4697, +44(0)1415484094

Fax: +44 (0)141552 2879

E-mail Address: rafet.kurt@ strath.ac.uk

Postal Address: Department of Naval Architecture, Ocean and Marine Engineering, University of Strathclyde, 100 Montrose Street, Glasgow G4 OLZ, United Kingdom 
In terms of human factors on-board ships, a naval architect's primary role is to design ships while considering the needs of crew in terms of health, wellbeing and performance. It is important to mention that the environment on ships in which crew members spend their day-to-day life is unique (motions, noise, vibrations, heat, cold, smell etc.) and can be considered as extreme when compared with many other industries. For example, one of the most challenging ship operations where human performance becomes critical is in arctic conditions, which is even compared by scientists to space operations (Sillitoe et al., 2010; Wickman). Moreover, as crew members not only work on board but are also required to live and rest in this same environment for months, crew performance and wellbeing become more complex. Therefore, environmental conditions on ships should be designed in a way to ensure not only the health but also the performance and wellbeing of crew members on board.

One of the most important environmental factors on ships is passive motions. Due to having obvious consequences and performance outcomes on crew, motion sickness has been studied in-depth, resulting in numerous human response models, which can be utilised to estimate the levels of comfort even at the design stage .However, shipping industry has failed to develop a similar knowledge base and even awareness on human response to noise, which are also very important environmental factors on board ships. Shipping industry focussed on complying with the limits set by IMO (International Maritime Organization), which were under scrutiny and forced to change recently.

This paper reports research conducted under the EU FP7 SILENV Project (Ships Oriented Innovative Solutions to Reduce Noise and Vibrations) which gave specific importance to human response to noise on board ships and produced a 'Green Label Standard' for noise levels on board ships.

\section{Literature Review}

The most obvious effect of noise on humans is called Temporary Threshold Shift (TTS) which is an auditory fatigue resulting from being exposed to hazardous levels of noise. Repeated exposure, not giving the affected person enough time to fully recover the TTS, or exposure to very hazardous levels of noise, progresses into a Permanent Threshold Shift (PTS) (Alberti, 2001). The current regulatory framework is only designed to protect workers from these hazardous noise exposures. However, effects of noise on crew is much wider than 
the health as it affects the crew wellbeing, comfort and performance considering that crew most of the time live and work in the same environment.

At this point it is important to mention two relevant noise standards which are applicable to ships. The IMO has recently updated the old Code on Noise Levels on Board Ships (IMO, 1981) with a new one (IMO, 2012) which is enforced under the provisions of regulation II-1/3-12 of the SOLAS Convention. The code defines the minimum acceptable noise levels for ship compartments and considers that, when complied with, the equivalent continuous noise exposure of crew members will not exceed $80 \mathrm{~dB}(\mathrm{~A})$. On the other hand, the EU Physical Agents Directive for Noise (EC, 2003) aims to protect the workers' health from hazardous noise exposures by defining the daily noise exposure action and limit values. In EU's approach, human is at focus and the aim is to monitor and regulate the total amount of noise received the crew. Therefore, exposure duration becomes more important since it directly affects the noise exposure levels. It may be inferred that the approach of EU Physical Agent Directive is more human oriented as compared to the aforementioned IMO Noise Code. However, both regulations are not strict enough when the effect of noise on crew performance and wellbeing is considered. Furthermore, the effect of noise on performance and wellbeing lacks research in the maritime domain. The aforementioned research gap and the need for diverting more research to this important area was also recognised by Martin and Kuo (1995).

Numerous research studies from other industrial sectors are focused on understanding the effect of noise exposure on worker performance and wellbeing. A review of the literature shows that exposure to noise has negative effects on human performance and wellbeing (Broadbent, 1954; Button et al., 2004; Kurt et al., 2010; Melamed et al., 2004; Melamed and Froom, 2002; Weston and Adams, 1932). However, it is also possible to find examples of studies in the literature where researchers found a positive relation or no relation between noise exposure and human performance (Harcum and Monti, 1973; Harrison and Kelly, 1989; Jerison, 1957; White et al., 2012).

The literature review thus demonstrates conflicting findings, which shows that the relationship between the noise exposure and human performance/wellbeing may change depending on the duration of noise exposure, type of noise, demography of the subjects, type and complexity of the task. Unfortunately, this situation makes the lessons-learnt from other industrial sectors to be less relevant and therefore less transferrable to the 
maritime domain. Therefore, effects of on-board noise levels on the human performance and wellbeing needs

1

to be investigated and findings should be taken into account when defining new noise limits for ships.

\section{Noise Criteria}

\subsection{IMO Noise Code}

The IMO Code on Noise Levels on Board Ships (resolution A.468 (XII)) has been in use for many years by regulatory bodies, ship owners and designers as permissible noise limits. Compliance with the limits defined by IMO noise code was voluntary, and therefore not every ship met the requirements of the code. Recently, some modifications were made to improve on the noise control/allowable exposure levels in the code (IMO, 2012), which came into force in January 2013, and is now mandatory to comply with. A comparison of the noise limits of the old and new code is given in Table 1 below.

Table 1: Noise level limits according to IMO Resolution A468 (XII) 1981 and IMO Resolution MSC.337 (91) 2012

\begin{tabular}{|c|c|c|c|}
\hline Locations & & $\begin{array}{l}\text { IMO } 1981 \\
\mathrm{~dB}(\mathrm{~A})\end{array}$ & $\begin{array}{l}\text { IMO } 2012 * \\
\mathrm{~dB}(\mathrm{~A})\end{array}$ \\
\hline \multirow[t]{5}{*}{ Work spaces } & Machinery spaces (continuously manned) & 90 & removed \\
\hline & Machinery spaces (not continuously manned) & 110 & 110 \\
\hline & Machinery control rooms & 75 & 75 \\
\hline & Workshops & 85 & 85 \\
\hline & Non-specified work spaces & 90 & 85 \\
\hline \multirow[t]{4}{*}{ Navigation spaces } & Navigation bridge and chartroom & 65 & 65 \\
\hline & $\begin{array}{l}\text { Listening post, including navigation bridge wings and } \\
\text { windows }\end{array}$ & 70 & 70 \\
\hline & $\begin{array}{l}\text { Radio room (with radio equipment operating but not } \\
\text { producing audio signals) }\end{array}$ & 60 & 60 \\
\hline & Radar rooms & 65 & 65 \\
\hline \multirow[t]{5}{*}{ Accommodation spaces } & Cabins and hospitals & 60 & $60 / 55$ \\
\hline & Mess rooms & 65 & $65 / 60$ \\
\hline & Recreation rooms & 65 & $65 / 60$ \\
\hline & Open recreation areas & 75 & 75 \\
\hline & Offices & 65 & $65 / 60$ \\
\hline \multirow[t]{2}{*}{ Service spaces } & Galleys, without food processing equipment operating & 75 & 75 \\
\hline & Stores and pantries & 75 & 75 \\
\hline Normally unoccupied spaces & Spaces not specified & 90 & 90 \\
\hline
\end{tabular}
*The limits for ship size greater than 10000 GRT are shown after $/$.

It can be seen from the above table that for some of the compartments the noise limits were reduced while other compartments noise limits remained same. Several classification societies and maritime authorities have already imposed more strict standards to control the ship noise (ABS, 2001; DMA, 2002; GL, 2003; LR, 
2004; MCA, 2007; SMA, 1973). It is stated in the code that, when ships comply with the noise limits defined

in Table 1, the equivalent continuous noise exposure of crew members will not exceed $80 \mathrm{~dB}(\mathrm{~A})$.

\subsection{EU Physical Agents Directive}

The European Parliament has followed a similar approach by issuing a physical agent directive to protect workers from risks arising from exposure to noise (EC, 2003). The directive covers all workers who are exposed or likely to be exposed to risk from noise. The main difference between the IMO resolution and the EU directive is that; the EU directive pays more attention to the workers' exposure to the noise and tries to limit hazardous exposures, while IMO aims to control noise at the design stage and enforce compartmentbased noise limits for ships to ensure the protection of human health on board. In a sense, it is a better approach to regulate the noise limits in a human-centred way but since ships are remote and monitoring compliance is harder, defining compartment based limits at the design stage is also effective. The exposure action and limit values defined by the EU physical agents directive is shown in Table 2.

Table 2: Exposure limit and action values defined by EU physical agents directive

\begin{tabular}{lll}
\hline & Daily exposure Levels, $\mathrm{dB}(\mathrm{A})$ & Peak levels, $\mathrm{dB}(\mathrm{C})$ \\
\hline Exposure limit values $\left(\mathrm{L}_{\mathrm{EX}}, 8 \mathrm{~h}\right)$ & 87 & 140 \\
Upper exposure action values $\left(\mathrm{L}_{\mathrm{EX}}, 8 \mathrm{~h}\right)$ & 85 & 137 \\
Lower exposure action values $\left(\mathrm{L}_{\mathrm{EX}}, 8 \mathrm{~h}\right)$ & 80 & 135 \\
\hline
\end{tabular}

For both EU Physical Agents Directive and IMO Noise Code, the exposure levels can be calculated using the following:

$\mathrm{L}_{E X, T}=10 \times \log \frac{1}{T} \sum_{i}^{n} t_{i} \times 10^{L i / 10}$

In the above equation $t_{i}$ is the duration in a noisy environment while $\mathrm{T}$ is 8 when calculating 8 hour equivalent exposure level and 24 when calculating 24 hour equivalent levels.

\subsection{Comparative Study}

In order to understand the current regulatory compliance, the authors conducted a comparative study on noise exposure on board ships (Turan et al., 2010) which included the following activities: 
- Noise levels at various compartments were measured in six different oil/chemical tankers during their sea trials.

- A questionnaire was designed and applied to capture the work patterns of the tanker crew.

- Based on the identified work patterns, noise exposure levels of all crew ranks were estimated.

- Results were comparatively analysed using the criteria defined by IMO and EU.

The main particulars of the six Oil/Chemical tanker ships are given in Table 3. It can be seen that all tankers are of similar size, apart from the "Oil/Chemical Tanker No: 4" which is a larger vessel.

Table 3: Main particulars of ships used in full scale measurements

\begin{tabular}{lllll}
\hline Type of Ship & DWT & L $_{\text {Overall }}$ (metres) & Speed (knots) & Engine Power $(\mathrm{kW})$ \\
\hline 1.Oil/Chemical Tanker & 7915 & 121 & 14 & 3840 \\
2.Oil/Chemical Tanker & 6000 & 107 & 13 & 2620 \\
3.Oil/Chemical Tanker & 8000 & 121 & 14 & 3840 \\
4.Oil/Chemical Tanker & 18000 & 148 & 14 & 5920 \\
5.Oil/Chemical Tanker & 4500 & 106 & 15.5 & 3250 \\
6.Oil/Chemical Tanker & 6100 & 123 & 13 & 2610 \\
\hline
\end{tabular}

It is stated in the IMO noise code that if ships comply with the defined noise limits seafarers will not be exposed to an $\operatorname{LEX}(24)$ exceeding $80 \mathrm{~dB}(\mathrm{~A})$. In order to investigate this, exposure levels for each rank were calculated through an exposure assessment tool reported in Turan et al. (2010). Results of this study showed that although ships are fulfilling the requirements set by the IMO on compartment bases, they are failing to comply with the defined noise exposure criteria. In the aforementioned study calculations were carried out for 4 different hearing protection levels; (1) no hearing protection used, (2) the IMO's estimated noise reduction levels are used, (3) a correction for using ' $\mathbf{A}$ ' weighted TWA (time weighted average) is applied to the noise reduction rates of hearing protectors, and (4) OSHA's correction factor from lab-obtained NRR (Noise Reduction Rating) to a real work environment is applied. It was concluded in this study that when all corrections applied on hearing devices to estimate their effective protection, seafarers, especially those who working in or near machinery spaces, are at risk. As a result it can be said that even in terms of protecting human health on board, there are issues that need to be improved. Therefore, it is necessary to introduce new norms, which will ensure designing the noise levels on board ships by considering the recent improvements, practical implementation, health, comfort and performance of crew members. 


\section{EU FP7 SILENV Project's Green Label Proposal}

EU FP7 SILENV Project (SILENV, 2009) was funded in response to an emerging need for reducing shipgenerated noise and vibration pollution. The SILENV Project dealt with a wide range of issues related to noise and vibration on and from ships which can be summarised in following three groups; (1) noise \& vibration onboard, (2) Underwater noise radiation, and (3) airborne noise emissions from ships. The project conducted a thorough review of the available published literature, carried out field studies and measurements, developed human response models, and issued guidelines aiming to improve the current situation (André et al., 2014; Badino et al., 2012a; Badino et al., 2012b, 2013; Borelli et al., 2015). One of the main deliverables of SILENV Project is the 'Green Label Proposal' (SILENV, 2012) which defines new improved noise limits for ships. The following sections will explain the development procedure as well as the final proposed green limits.

\subsection{Methodology}

In order to define the SILENV Green Label, the following methodology was adopted as demonstrated in Figure 1 below.

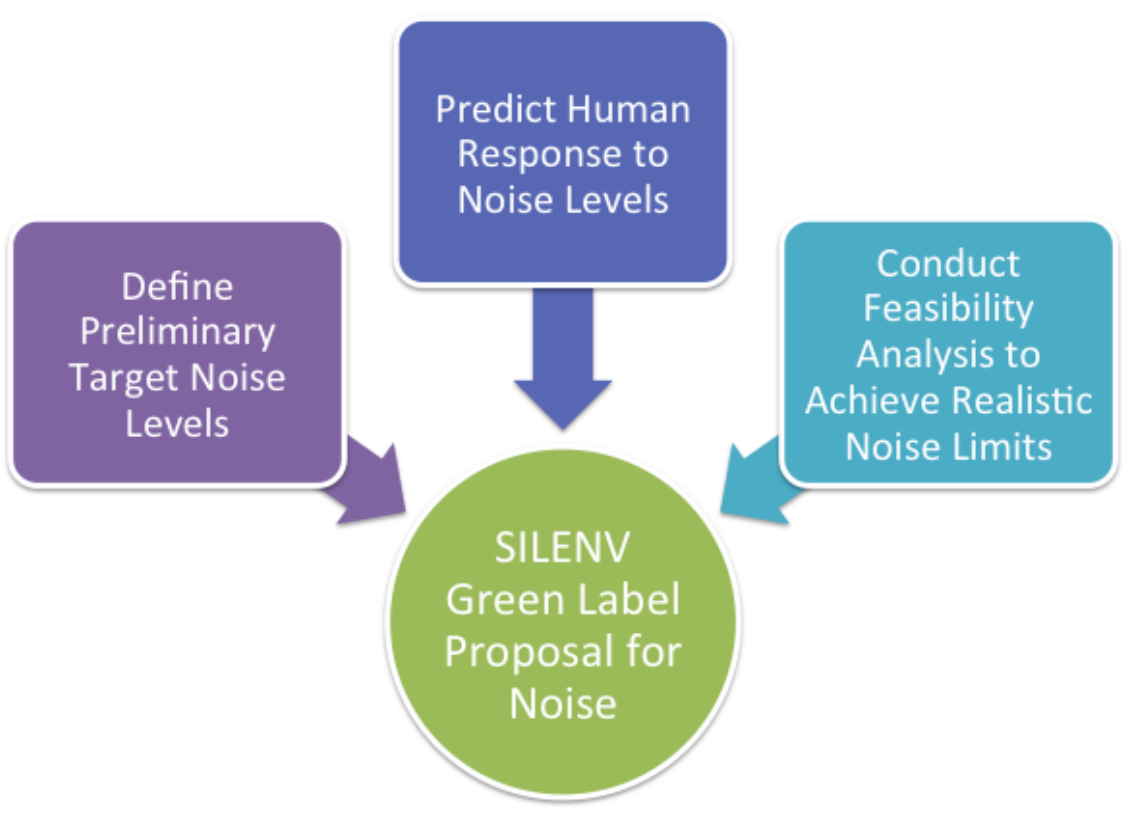

Figure 1: SILENV Approach for defining noise limits 
First, the SILENV Consortium aimed to define preliminary target levels for noise on board ships. In order to achieve this, a comprehensive research was conducted to review all applicable noise standards and regulations.

In the next step, the SILENV Project investigated the resulting human response from preliminary noise levels as defined in the previous step. Specific human response models (comfort, wellbeing and performance) were developed to predict the human response. These models were then utilised to take human response into consideration.

It was also important to define noise limits which are achievable and which will be accepted by the industry. Therefore, in the SILENV project a database of noise measurement levels from European ships was built, so that proposed levels could be assessed to see whether it is feasible for current fleet to comply with or not.

Finally, the SILENV Consortium finalised the Green Label Proposal through an expert workshop.

\subsection{Preliminary targets and critical analysis}

The IMO "Code on noise levels on board ships" is fully accepted by the maritime community as a reference document when dealing with noise on board ships. Therefore, it was considered that the development of preliminary noise limits for the SILENV 'Green Label Proposal' should use the IMO noise code as a base. Then, through conducting an extensive review on available noise norms, target noise levels were developed. It was thought that SILENV should consider all the limit levels defined by the various existing norms and define the preliminary target noise levels which -if not more stringent- are just as stringent as the existing norms to ensure compliance with the most demanding noise mitigation standards for comfort and work environment.

The proposed preliminary noise levels are shown in Table 4 and Table 5 for crew and passengers respectively, in comparison with the existing norms. 
Table 4: Proposed preliminary noise limits for crew spaces in comparison with existing norms (in $\mathrm{dB}(\mathrm{A})$ )

1

$2^{2}$

3

4

5

6

7

8

(SILENV, 2012)

\begin{tabular}{|c|c|c|c|c|c|c|c|c|c|c|}
\hline & Locations & RINA & $\mathrm{BV}$ & GL & $\mathrm{ABS}$ & DNV & LR & $\begin{array}{l}\text { IMO } \\
\text { Code }\end{array}$ & $\begin{array}{l}\text { IMO } \\
\text { New }\end{array}$ & PROPOSED \\
\hline \multirow{11}{*}{ 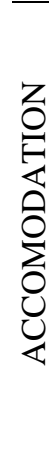 } & Crew Cabins & 55 & 52 & 52 & 50 & 50 & 52 & 60 & 55 & 50 \\
\hline & Day Cabins & - & - & - & - & - & 55 & - & - & 55 \\
\hline & Officers Cabins & 52 & - & 50 & - & - & - & - & - & 50 \\
\hline & Hospital & 50 & 55 & 54 & 50 & 55 & - & 60 & 60 & 50 \\
\hline & Offices & 58 & 57 & 57 & 55 & 60 & 55 & 65 & 65 & 55 \\
\hline & Open deck recreation & 70 & 70 & 68 & 65 & 70 & - & 75 & 70 & 65 \\
\hline & Closed Public Spaces & 60 & 57 & 90 & - & 55 & - & - & - & 55 \\
\hline & Mess room & 60 & 57 & 57 & - & - & 57 & 65 & 60 & 57 \\
\hline & Recreation & - & - & 57 & 60 & - & - & 65 & 65 & 57 \\
\hline & Corridors & - & 70 & 58 & 60 & - & - & - & - & 58 \\
\hline & Dining Spaces & - & - & - & 55 & - & - & - & - & 55 \\
\hline \multirow{5}{*}{ 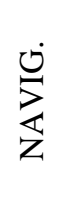 } & & 58 & 55 & 55 & 55 & 55 & 60 & 60 & 65 & 55 \\
\hline & Radio room & & & & & & & & & \\
\hline & Navigation Spaces & 58 & - & 55 & - & - & - & 65 & - & 55 \\
\hline & Chart Rooms & - & - & - & 55 & - & - & - & - & 55 \\
\hline & Radar Room & - & - & - & 55 & - & - & 65 & - & 55 \\
\hline \multirow{16}{*}{ 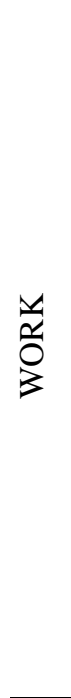 } & & 70 & 70 & 67 & 65 & 70 & 75 & 75 & 70 & 65 \\
\hline & Engine control room & & & & & & & & & \\
\hline & Workshops & - & 85 & 80 & 80 & - & 85 & 80 & 80 & 80 \\
\hline & Open deck working areas & 70 & & 75 & - & - & 63 & - & - & 63 \\
\hline & Laundries & - & - & - & 75 & - & - & - & - & 75 \\
\hline & Continuously Manned Machinery Spaces & - & - & - & 85 & - & 90 & 90 & - & 85 \\
\hline & Not Continuously Manned Machinery & - & - & 110 & 108 & - & 110 & 110 & 105 & 105 \\
\hline & Spaces & & & & & & & & & \\
\hline & Cargo Handling Spaces/Areas Near Cargo & - & - & - & 80 & - & - & - & - & 80 \\
\hline & Fan Rooms & - & - & - & 85 & - & - & - & - & 85 \\
\hline & Alleyways, changing rooms & - & - & - & - & - & 70 & - & - & 70 \\
\hline & Listing posts, Bridge wings & - & - & 65 & - & - & - & 70 & 70 & 65 \\
\hline & Galleys & - & 70 & 68 & 70 & - & 75 & - & 70 & 68 \\
\hline & Pantries & - & - & 66 & 70 & - & - & - & - & 66 \\
\hline & Stores & - & - & 80 & 70 & - & - & - & - & 70 \\
\hline & Wheelhouse & - & - & - & 55 & 60 & 85 & - & 65 & 55 \\
\hline
\end{tabular}

Table 5: Proposed preliminary noise limits for passenger compartments

\begin{tabular}{llllllll}
\hline \multirow{2}{*}{ Locations } & & \multicolumn{6}{c}{ Noise Level, dB(A) } \\
\hline Passenger top level cabins & ABS & BV & DNV & GL & LR & RINA & PROPOSED \\
Passenger standard cabins & 45 & 45 & 44 & 44 & 45 & 45 & $\mathbf{4 4}$ \\
Outside installation & 65 & 49 & 49 & 46 & 49 & 50 & $\mathbf{4 5}$ \\
Discotheque, ballroom & 65 & 65 & 64 & 67 & 65 & $\mathbf{6 4}$ \\
Restaurant, lounge & 55 & 65 & 55 & 52 & 55 & 55 & $\mathbf{5 2}$ \\
Libraries, theatre & 55 & 53 & 55 & 52 & 55 & 55 & $\mathbf{5 2}$ \\
Shops & 55 & 60 & 55 & 52 & 50 & 52 & $\mathbf{5 0}$ \\
Gymnasium & 65 & 60 & 55 & 52 & 65 & 55 & $\mathbf{5 2}$ \\
Corridors, staircase & 60 & 60 & 55 & 54 & 55 & 60 & $\mathbf{5 4}$ \\
Hospital & 45 & 55 & 55 & 54 & 52 & 50 & $\mathbf{4 5}$ \\
\hline
\end{tabular}




\subsection{Human Response}

As already highlighted in Section 3.3, the study on the compliance of existing vessels with IMO regulation and EU directive, revealed that in some cases the ships fulfilling limiting noise level criteria of IMO regulation were still failing to meet the noise exposure limits (see Turan et al., 2010). It was, therefore, considered important to assess the preliminary noise target levels against human subjective responses from on board comfort and work environment point of view. Hence, improved human response models were developed in the SILENV Project (see Houben et al., 2012 for further details). For the model development, noise measurements were conducted in various compartments on board 15 different ships. Together with the noise measurements, questionnaires were deployed to capture the human response. The human response models describe the relationship between the levels of noise and subjective ratings of crew on performance and of passengers on comfort. The number of various ordinal subjective ratings obtained were reduced through correlation, factor analyses and common sense. The relationship between dependent and independent variables appeared to be non-linear, hence logistic regressions were used and final models with good fitness were obtained.

In order to represent multidimensional nature of human responses, 2 comfort and 3 performance models were developed, resulting in a total of 5 human response models focusing on different performance and comfort criteria. These models are summarized in Table 6.

Table 6: Dependent variable in models. Numbers only refer to specific items used in the questionnaires deployed in the SILENV Project, and are of no particular value here.

\begin{tabular}{ll}
\hline & Models \& Dependent variables \\
\hline Comfort & N2c - Annoyance \\
& O1c - Overall feeling of discomfort \\
& N2p - Annoyance \\
Performance & N7p - Quality impairment \\
& O1p - Overall feeling of wellbeing \\
\hline
\end{tabular}

As a result of detailed discussions amongst SILENV partners, for comfort 'N2c - Noise Annoyance model' and for performance 'N7p - Quality impairment model' were selected out of a larger range of questionnaire items deployed by the SILENV Project to assess the preliminary target levels. These selected models were then used to calculate the percentage of human discomfort and performance impairment. Table 7 shows the 
limits corresponding to a specific percentage of people annoyed or impaired in their work by the noise. In the SILENV Green Label proposal it was aimed to ensure at least $90 \%$ of passengers' and crews' satisfaction.

Table 7: Noise limits per human response

\begin{tabular}{lll}
\hline Extra probability relative to base line & Noise Annoyance, $\mathrm{dB}(\mathrm{A})$ & Noise Induced Work Quality Impairment, $\mathrm{dB}(\mathrm{A})$ \\
\hline $5 \%$ & 48 & 55 \\
$10 \%$ & 55 & 64 \\
$15 \%$ & 60 & 71 \\
$20 \%$ & 65 & 77 \\
$25 \%$ & 70 & 82 \\
$30 \%$ & 75 & 86 \\
\hline
\end{tabular}

\subsection{Feasibility of the Preliminary Target Levels}

It is important to define realistic noise limits which are achievable for new ships. Therefore, the aim of this analysis was to find an answer to the following question: "what noise criteria should be defined in order to make only $5 \%, 10 \%, 20 \%, 30 \%, 40 \%$, and $50 \%$ of modern ships to comply?". In order to achieve that, only the most recent ships from the SILENV Noise Database were selected considering that the technology in older ships will not be comparable to the new buildings. A total of 64 different vessels were taken into consideration and Table 8 shows the percentages of vessels from the SILENV database that comply with the noise levels. Noise limits which will correspond to $20 \%$ of the vessels to comply, was considered reasonable and achievable by the SILENV Consortium. More details about the SILENV database can be found in a publication by Beltrán Palomo (2013)

\subsection{Finalisation of Green Label Proposal}

The noise requirements defined in previous sections were combined to obtain the SILENV Green Label Proposal. First, the preliminary noise limits (IMO limits as well as other standards) were taken as a starting point and compared to the human response criteria defined in the previous sections. As a result of this comparison and discussions, new noise limits were defined (see Houben et al., 2012 for details). Then, these noise limits were compared with the noise criteria based on $20 \%$ of current vessels compliance. Again, after these comparison and discussions within the SILENV Consortium, new noise limits have been defined. After consolidating all the criteria, through a workshop SILENV partners further discussed and finalised the green label proposal. The final SILENV Green Label Proposal is shown in Table 9 below. As it can be seen from the table, SILENV introduced its own space groups, similar but not completely identical to the compartments specified by IMO (Table 1). 
Table 8: Percentages of vessels which comply with given noise levels (SILENV, 2012) for the different locations and corresponding location types as defined in Table 10.

\begin{tabular}{|c|c|c|c|c|c|c|c|c|c|c|c|c|c|}
\hline \multirow[b]{2}{*}{ Locations } & \multirow{2}{*}{$\begin{array}{l}\text { Correspo } \\
\text { nding } \\
\text { location } \\
\text { type }\end{array}$} & \multicolumn{2}{|c|}{$x=50 \%$} & \multicolumn{2}{|c|}{$x=40 \%$} & \multicolumn{2}{|c|}{$x=30 \%$} & \multicolumn{2}{|c|}{$x=20 \%$} & \multicolumn{2}{|c|}{$\mathrm{x}=10 \%$} & \multicolumn{2}{|c|}{$x=5 \%$} \\
\hline & & $\begin{array}{l}\text { Noise } \\
\text { limit } \\
\mathrm{dB}(\mathrm{A})\end{array}$ & $\begin{array}{l}\text { Exact } \\
\text { percen } \\
\text { t. } \%\end{array}$ & $\begin{array}{l}\text { Noise } \\
\text { limit } \\
\mathrm{dB}(\mathrm{A})\end{array}$ & $\begin{array}{l}\text { Exact } \\
\text { percen } \\
\text { t. } \%\end{array}$ & $\begin{array}{l}\text { Noise } \\
\text { limit } \\
\mathrm{dB}(\mathrm{A})\end{array}$ & $\begin{array}{l}\text { Exact } \\
\text { percen } \\
\text { t. } \%\end{array}$ & $\begin{array}{l}\text { Noise } \\
\operatorname{limit} \\
\operatorname{dB}(A)\end{array}$ & $\begin{array}{l}\text { Exact } \\
\text { perce } \\
\text { nt. \% }\end{array}$ & $\begin{array}{l}\text { Noise } \\
\text { limit } \\
\mathrm{dB}(\mathrm{A})\end{array}$ & $\begin{array}{l}\text { Exact } \\
\text { percen } \\
\text { t. } \%\end{array}$ & $\begin{array}{l}\text { Noise } \\
\text { limit } \\
\mathrm{dB}(\mathrm{A})\end{array}$ & $\begin{array}{l}\text { Exact } \\
\text { percen } \\
\text { t. } \%\end{array}$ \\
\hline $\begin{array}{l}\text { Passenger } \\
\text { Cabin }\end{array}$ & 1 & 54 & 46 & 54 & 39 & 51 & 31 & 50 & 27 & 46 & 12 & 44 & 4 \\
\hline Crew Cabin & 1 & 60 & 52 & 59 & 41 & 57 & 33 & 54 & 19 & 51 & 11 & 49 & 7 \\
\hline Offices & 2 & 59 & 49 & 58 & 42 & 55 & 32 & 52 & 25 & 51 & 14 & 49 & 7 \\
\hline Public Spaces & 3 & 60 & 52 & 59 & 44 & 57 & 32 & 56 & 24 & 55 & 12 & 52 & 4 \\
\hline $\begin{array}{l}\text { Crew Public } \\
\text { Spaces }\end{array}$ & 4 & 66 & 49 & 65 & 42 & 63 & 34 & 60 & 20 & 53 & 10 & 50 & 4 \\
\hline Outdoor Areas & 6 & 76 & 47 & 76 & 40 & 74 & 27 & 69 & 20 & 59 & 13 & 59 & 13 \\
\hline Wheelhouse & 7 & 62 & 54 & 61 & 42 & 58 & 31 & 57 & 23 & 55 & 12 & 54 & 5 \\
\hline Work Spaces & 9 & 83 & 53 & 82 & 40 & 79 & 31 & 76 & 18 & 73 & 10 & 69 & 6 \\
\hline Control Room & 8 & 70 & 51 & 69 & 40 & 66 & 30 & 62 & 23 & 60 & 11 & 58 & 4 \\
\hline $\begin{array}{l}\text { Auxiliary } \\
\text { Engine Room }\end{array}$ & 11 & 105 & 46 & 104 & 39 & 102 & 23 & 97 & 15 & 89 & 8 & 79 & 0 \\
\hline Engine Room & 11 & 108 & 50 & 107 & 40 & 106 & 27 & 105 & 21 & 102 & 10 & 101 & 8 \\
\hline
\end{tabular}

Table 9: Locations used for the SILENV Green Noise Label

\begin{tabular}{|c|c|c|c|}
\hline Location Type & Group Name & Location Example & Noise Limits, $\mathrm{dB}(\mathrm{A})$ \\
\hline \multirow[t]{3}{*}{1} & \multirow{3}{*}{ Cabins } & Passenger Cabins & 50 \\
\hline & & Crew Cabins & 50 \\
\hline & & Hospital & 50 \\
\hline 2 & Offices & Offices & 53 \\
\hline \multirow[t]{2}{*}{3} & \multirow[t]{2}{*}{ Public Spaces A } & Libraries & 55 \\
\hline & & Calm Public Spaces & 55 \\
\hline \multirow[t]{4}{*}{4} & \multirow[t]{4}{*}{ Public Spaces B } & Restaurant & 60 \\
\hline & & Lounge & 60 \\
\hline & & Mess room & 60 \\
\hline & & Shops & 60 \\
\hline \multirow[t]{4}{*}{5} & \multirow[t]{4}{*}{ Public Spaces C } & Discotheque, dance floor & 65 \\
\hline & & Ball room & 65 \\
\hline & & Corridor & 65 \\
\hline & & Staircase & 65 \\
\hline \multirow[t]{2}{*}{6} & \multirow[t]{2}{*}{ Outdoor Areas } & Open recreational areas & 70 \\
\hline & & Bridge wings / Open deck working areas & 70 \\
\hline \multirow[t]{2}{*}{7} & \multirow[t]{2}{*}{ Wheelhouse } & Wheelhouse & 60 \\
\hline & & Radio Room & 60 \\
\hline \multirow[t]{2}{*}{8} & \multirow[t]{2}{*}{ Work space A } & Engine Control Room & 65 \\
\hline & & Galleys & 65 \\
\hline \multirow[t]{5}{*}{9} & \multirow[t]{5}{*}{ Work space B } & Pantries & 75 \\
\hline & & Stores & 75 \\
\hline & & Laundries & 75 \\
\hline & & Workshops & 75 \\
\hline & & Garage & 75 \\
\hline 10 & Work space $\mathrm{C}$ & Continuously manned machinery space & 90 \\
\hline 11 & Work space D & Not Continuously manned machinery space & 105 \\
\hline
\end{tabular}




\section{Conclusions}

In the SILENV Project improved human response models have been developed (Kurt, 2014). Furthermore, these models were utilised for developing the SILENV green label proposal. The noise criteria proposed by SILENV is the first example of a human oriented noise norm developed for the shipping industry. The developed green label proposal not only aims to protect the health of the crew but also aims to maintain a good level of comfort as well as performance on board ships, also for passengers. Analysis of current fleet shows that, the new limits are realistic and achievable by the new ships. More information can be seen in the SILENV Green label proposal (SILENV, 2012).

The SILENV Green Label stands out by the following issues:

- The difference made by classification societies between crew cabins and passenger cabins is removed. The main reason for this is related to the minimum standards of wellbeing of human regardless of their role onboard ships. $50 \mathrm{~dB}(\mathrm{~A})$ is an achievable noise level for both passenger and crew and provides a basic standard. Crew being able to sleep and rest is very critical since sleep deprivation is identified as one of the contributors to crew fatigue, which is leading to human errors and ship accidents/incidents. For passenger ships, different classification societies offer various comfort class notations that differentiate in the level of quietness of the room. However, crew who live and work onboard ships do not have such choices and it is very important that they at least receive the cabin equivalent to the minimum standard of a passenger cabin for a given ship. Therefore, $50 \mathrm{~dB}(\mathrm{~A})$ is a desirable and technologically achievable minimum standard for crew cabins considering both crew wellbeing and safer ship operations.

- Another point is that even in the new IMO noise code, the noise limit defined for the hospital location is $60 \mathrm{~dB}(\mathrm{~A})$, which is $10 \mathrm{~dB}(\mathrm{~A})$ higher when compared to the SILENV proposed limit of $50 \mathrm{~dB}(\mathrm{~A})$. The main reason for a more stringent SILENV limit is that any patient admitted to the hospital section of the ship, should have the ideal conditions for fast recovery and at least they should have the minimum cabin standards.

- Noise levels in cabins were specified to ensure that less than $10 \%$ of people will get annoyed. Tolerating a small percentage of people being annoyed is based on the fact that, even in the absence of 
any physical environmental habitat deficiencies, average complaints are around $10 \%$, which is attributed mainly to the passenger expectations and personal or other factors such as price vs service (Turan, 2006). Therefore achieving 90\% satisfaction level was considered feasible and more realistic.

- Noise levels in wheelhouses have been specified to ensure that less than $10 \%$ of people will judge their performance degraded based on subjectively reported self ratings. Again, considering safe operations, a lower noise limit in the wheel house (bridge) is necessary. Study carried out by Kurt et al. (2010) shows that increasing noise levels on the bridge influence the concentration of the officer and affect the passage performance significantly. Therefore, the limit set by IMO of $65 \mathrm{~dB}(\mathrm{~A})$ should be further investigated.

- In high noise areas (Work space C and D) hearing protection has to be worn. Previous studies showed that noise exposure of crew mainly working in engine and related rooms exceeds the exposure limits defined by the EU physical agents directive (Turan et al., 2010). It is clear that reducing the noise levels in engine rooms or similar compartments to an inhabitable level is not always possible. Therefore, Personal Protective Equipment (PPE) is essential to be worn by the crew who work in these spaces. There are various types of PPEs available providing different levels of protection against noise. Therefore, it is important to choose the correct type of hearing protection to reduce the hazardous noise exposure.

- When considering the public spaces, the proposed SILENV standards took into account the activities taking place in those spaces as well as human expectations. This resulted in the proposal of different limits. The noise level in public spaces such as libraries is expected to be low and therefore a lower noise limit, corresponding with a lower annoyance level (10\%) is chosen. On the other hand, in public spaces like dining spaces or shops, noise levels are naturally higher due to the leisure activities and therefore noise limits are chosen to be less stringent, corresponding with $15 \%$ annoyance level.

Overall, the proposed SILENV Green Label Noise standards advocate to consider not only health but also wellbeing and performance of humans on board. It was also shown that these proposed standards can be achieved by the industry with currently available technologies and know-how. 


\section{Acknowledgement}

1

Authors gratefully acknowledge that the research presented in this paper is generated as part of European Commission funded project SILENV (Ships Oriented Innovative Solutions to Reduce Noise and Vibrations), Seventh Framework Programme, Project number 234182, FP7-SST-2008-RTD-1. 


\section{References}

ABS, 2001. Guide for Crew Habitability on Ships. American Bureau of Shipping.

Alberti, P.W., 2001. The Pathophysiology of the Ear, in: Goelzer B, H.C., Sehrndt GA (Ed.), Occupational Exposure To Noise Evaluation, Prevention And Control. World Health Organisation (WHO).

André, M., Baudin, E., Palomo, P.B., Dambra, R., Delente, M., Gaggero, T., Haimov, E., Hallander, J., Houben, M., Ianniello, S., 2014. Holistic noise and vibration abatement within the EU 7FP. The SILENV project: Ship Innovative soLutions to rEduce Noise and Vibrations. Transport Research Arena.

Badino, A., Borelli, D., Gaggero, T., Rizzuto, E., Schenone, C., 2012a. Control of airborne noise emissions from ships, Proc. of the Intern. Conf. on Advances and Challenges in Marine Noise and Vibration MARNAV2012, Glasgow, UK.

Badino, A., Borelli, D., Gaggero, T., Rizzuto, E., Schenone, C., 2012b. Noise emitted from ships: impact inside and outside the vessels. Procedia-Social and Behavioral Sciences 48, 868-879.

Badino, A., Borelli, D., Gaggero, T., Rizzuto, E., Schenone, C., 2013. The EU research effort towards the control of noise emissions from ships: the SILENV Project (7FP), AIA-DAGA 2013 Conference on Acoustics, Merano, Italy.

Baker, C.C., Seah, A.K., 2004. Maritime accidents and human performance: the statistical trail, MarTech Conference, Singapore.

Beltrán Palomo, P., 2013. The Most Recent Noise \& Vibration Assessment of the European Fleet, within the Framework of the "SILENV Project". Ship Science \& Technology 7 (14), 43-66.

Borelli, D., Gaggero, T., Rizzuto, E., Schenone, C., 2015. Measurments of airborne noise emitted by a ship at quay, The 22nd International Congress on Sound and Vibration Florence, Italy.

Bos, J.E., MacKinnon, S.N., Patterson, A., 2005. Motion sickness symptoms in a ship motion simulator: effects of inside, outside, and no view. Aviation, space, and environmental medicine 76 (12), 1111-1118.

Broadbent, D.E., 1954. Some effects of noise on visual performance. Quarterly Journal of Experimental Psychology 6 (1), 1-5.

Button, D.C., Behm, D.G., Holmes, M., Mackinnon, S.N., 2004. Noise and muscle contraction affecting vigilance task performance. Occupational Ergonomics 4 (3), 157-171.

DMA, 2002. Technical regulation on noise in ships, Technical regulation 4. Danish Maritime Authority.

EC, 2003. on the minimum health and safety requirements regarding the exposure of workers to the risks arising from physical agents (noise). Official Journal of the European Union.

GL, 2003. Rules for Classification and Construction, Chapter 16 Harmony Class- Rules on Rating. Germanischer Lloyd

Harcum, E.R., Monti, P.M., 1973. Cognitions and Placebos in Behavioural Research on Ambient Noise. Perceptual and Motor Skills 37 (1), 75-99.

Harrison, D.W., Kelly, P.L., 1989. Age differences in cardiovascular and cognitive performance under noise conditions. Perceptual and Motor Skills 69 (2), 547-554. 
Houben, M., Kurt, R.E., Khalid, H., Zoet, P., Bos, J., Turan, O., 2012. Human Response to Noise and Vibration Aboard Ships, International Conference on Advances and Challenges in Marine Noise and Vibration. University of Strathclyde, 5-7 September, Glasgow UK.

IMO, 1981. Code on Noise Levels on Board Ships.

IMO, 2012. Adoptation of the Code on Noise Levels on Board Ships. International Maritime Organisation.

Jerison, H.J., 1957. Performance on a simple vigilance task in noise and quiet. The Journal of the Acoustical Society of America 29 (11), 1163-1165.

Khalid, H., Turan, O., Bos, J.E., 2011. Theory of a subjective vertical-horizontal conflict physiological motion sickness model for contemporary ships. Journal of marine science and technology 16 (2), 214-225.

Kurt, R.E., 2014. Development of human response models and human oriented criteria for noise on board ships, Department of Naval Architecture, Ocean and Marine Engineering. University of Strathclyde, Glasgow, United Kingdom.

Kurt, R.E., Turan, O., Arslan, O., H., K., Clelland, D., Gut, N., 2010. An Experimental Study to Investigate Effects of Noise on Human Performance Onboard Ships, Human Performance at Sea Conference, Glasgow, UK.

\section{LR, 2004. Provisional Rules for Passenger and Crew Accommodation Comfort. Lloyd's Register.}

Martin, A., Kuo, C., 1995. The effects of noise and vibration on crew performance, International Conference on Noise and Vibration in the Maritime Environment. The Royal Institution of Naval Architects Trinity House, London, UK.

MCA, 2007. Codes of Practice For Controlling Risks due to Noise and Vibration on Ships. Maritime and Coastguard Agency

McCauley, M.E., Royal, J.W., Wylie, C.D., O'Hanlon, J.F., Mackie, R.R., 1976. Motion sickness incidence: Exploratory studies of habituation, pitch and roll, and the refinement of a mathematical model. DTIC Document.

Melamed, S., Fried, Y., Froom, P., 2004. The joint effect of noise exposure and job complexity on distress and injury risk among men and women: the cardiovascular occupational risk factors determination in Israel study. Journal of occupational and environmental medicine 46 (10), 1023-1032.

Melamed, S., Froom, P., 2002. The joint effect of industrial noise exposure and job complexity on all-cause mortality-The CORDIS study. Noise and Health 4 (16), 23.

SILENV, 2009. Ships oriented innovative solutions to reduce noise and vibrations. European Union, Framework Programme 7 Collaborative Project no 234182.

SILENV, 2012. WP 5: Green Label Proposal - Subtask 5.2: Noise and Vibration label proposal.

Sillitoe, A., Upcraft, D., Rich, K., LaRoche, M., Røed, B., Huse, J., 2010. Supporting Human Performance in Ice and Cold Conditions. Lloyd's Register, London.

SMA, 1973. Sjöfartsverkets meddelanden Serie A. Swedish Maritime Authority.

Turan, O., 2006. COMPASS Final Publishable Report A rational approach for reduction of motion sickness \& improvement of passenger comfort \& safety in sea transportation. 
1

Turan, O., Helvacioglu, I.H., Insel, M., Khalid, H., Kurt, R.E., 2010. Crew noise exposure on board ships and comparative study of applicable standards. Ships and Offshore Structures 6 (4), 323-338.

Weston, H.C., Adams, S., 1932. The effects of noise on the performance of weavers. Medical Research Council Industrial Health Research Board, pp. 38-62.

White, K., Meeter, M., Bronkhorst, A., 2012. Effects of transportation noise and attitudes on noise annoyance and task performance, INTER-NOISE and NOISE-CON Congress and Conference Proceedings. Institute of Noise Control Engineering, pp. 780-788.

Wickman, L.A., Comparing Crew Operations in Extreme Environments: Arctic Shipping vs. Outer Space. 


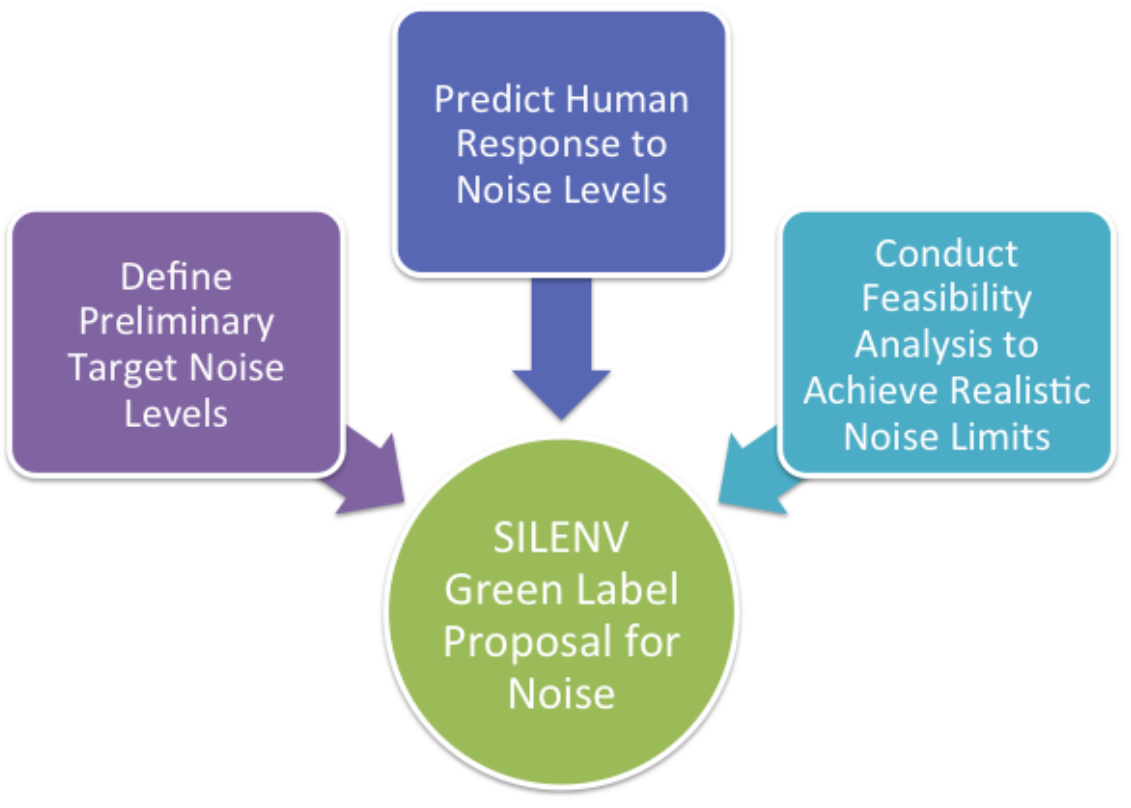

Figure 1: SILENV Approach for defining noise limits 


\begin{tabular}{llll}
\hline Locations & & $\begin{array}{l}\text { IMO 1981 } \\
\text { dB(A) }\end{array}$ & $\begin{array}{l}\text { IMO 2012* } \\
\text { dB(A) }\end{array}$ \\
\hline Work spaces & Machinery spaces (continuously manned) & 90 & removed \\
& Machinery spaces (not continuously manned) & 110 & 110 \\
& Machinery control rooms & 75 & 75 \\
& Workshops & 85 & 85 \\
& Non-specified work spaces & 90 & 85 \\
Navigation spaces & Navigation bridge and chartroom & 65 & 65 \\
& Listening post, including navigation bridge wings and & 70 & 70 \\
& windows & & 60 \\
& Radio room (with radio equipment operating but not & 60 & \\
& producing audio signals) & 65 & 65 \\
Radar rooms & & $60 / 55$ \\
Accommodation spaces & Cabins and hospitals & 60 & $65 / 60$ \\
& Mess rooms & 65 & $65 / 60$ \\
& Recreation rooms & 65 & 75 \\
Open recreation areas & 75 & $65 / 60$ \\
Offices & 65 & 75 \\
Service spaces & Galleys, without food processing equipment operating & 75 & 75 \\
& Stores and pantries & 75 & \\
Normally unoccupied spaces & Spaces not specified & & 90 \\
\hline
\end{tabular}

*The limits for ship size greater than 10000 GRT are shown after/.

Table 2: Exposure limit and action values defined by EU physical agents directive

\begin{tabular}{lll}
\hline & Daily exposure Levels, $\mathrm{dB}(\mathrm{A})$ & Peak levels, $\mathrm{dB}(\mathrm{C})$ \\
\hline Exposure limit values $\left(\mathrm{L}_{\mathrm{EX}}, 8 \mathrm{~h}\right)$ & 87 & 140 \\
Upper exposure action values $\left(\mathrm{L}_{\mathrm{EX}}, 8 \mathrm{~h}\right)$ & 85 & 137 \\
Lower exposure action values $\left(\mathrm{L}_{\mathrm{EX}}, 8 \mathrm{~h}\right)$ & 80 & 135 \\
\hline
\end{tabular}

Table 3: Main particulars of ships used in full scale measurements

\begin{tabular}{lllll}
\hline Type of Ship & DWT & L $_{\text {Overall }}($ metres $)$ & Speed (knots) & Engine Power $(\mathrm{kW})$ \\
\hline 1.Oil/Chemical Tanker & 7915 & 121 & 14 & 3840 \\
2.Oil/Chemical Tanker & 6000 & 107 & 13 & 2620 \\
3.Oil/Chemical Tanker & 8000 & 121 & 14 & 3840 \\
4.Oil/Chemical Tanker & 18000 & 148 & 14 & 5920 \\
5.Oil/Chemical Tanker & 4500 & 106 & 15.5 & 3250 \\
6.Oil/Chemical Tanker & 6100 & 123 & 13 & 2610 \\
\hline
\end{tabular}




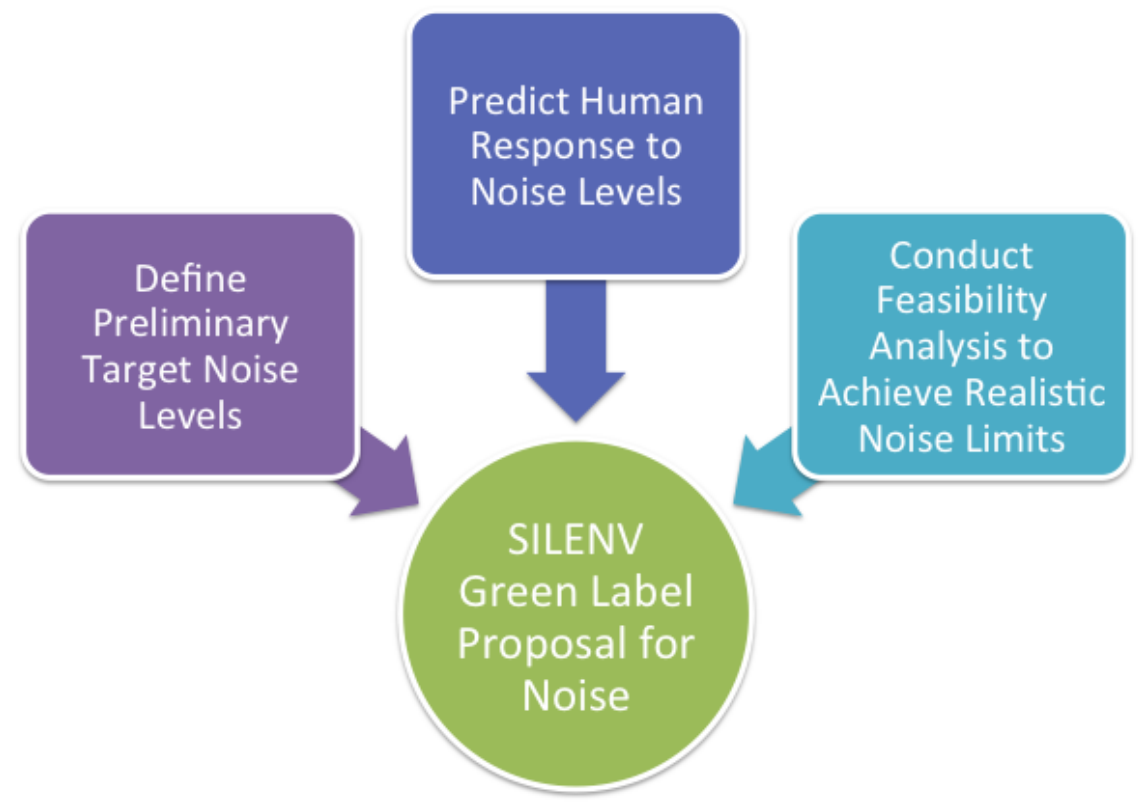

Figure 1: SILENV Approach for defining noise limits

Table 4: Proposed preliminary noise limits for crew spaces in comparison with existing norms (in $\mathrm{dB}(\mathrm{A})$ )

(SILENV, 2012)

\begin{tabular}{|c|c|c|c|c|c|c|c|c|c|c|}
\hline & Locations & RINA & BV & GL & ABS & DNV & LR & $\begin{array}{l}\text { IMO } \\
\text { Code }\end{array}$ & $\begin{array}{l}\text { IMO } \\
\text { New }\end{array}$ & PROPOSED \\
\hline \multirow{12}{*}{ 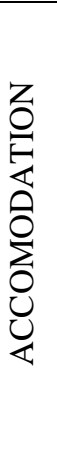 } & Crew Cabins & 55 & 52 & 52 & 50 & 50 & 52 & 60 & 55 & 50 \\
\hline & Day Cabins & - & - & - & - & - & 55 & - & - & 55 \\
\hline & Officers Cabins & 52 & - & 50 & - & - & - & - & - & 50 \\
\hline & Hospital & 50 & 55 & 54 & 50 & 55 & - & 60 & 60 & 50 \\
\hline & Offices & 58 & 57 & 57 & 55 & 60 & 55 & 65 & 65 & 55 \\
\hline & Open deck recreation & 70 & 70 & 68 & 65 & 70 & - & 75 & 70 & 65 \\
\hline & Closed Public Spaces & 60 & 57 & 90 & - & 55 & - & - & - & 55 \\
\hline & Mess room & 60 & 57 & 57 & - & - & 57 & 65 & 60 & 57 \\
\hline & Recreation & - & - & 57 & 60 & - & - & 65 & 65 & 57 \\
\hline & Corridors & - & 70 & 58 & 60 & - & - & - & - & 58 \\
\hline & Dining Spaces & - & - & - & 55 & - & - & - & - & 55 \\
\hline & & 58 & 55 & 55 & 55 & 55 & 60 & 60 & 65 & 55 \\
\hline \multirow{4}{*}{$\stackrel{\substack{Z \\
Z}}{\underset{z}{Z}}$} & Radio room & & & & & & & & & \\
\hline & Navigation Spaces & 58 & - & 55 & - & - & - & 65 & - & 55 \\
\hline & Chart Rooms & - & - & - & 55 & - & - & - & - & 55 \\
\hline & Radar Room & - & - & - & 55 & - & - & 65 & - & 55 \\
\hline \multirow{8}{*}{$\begin{array}{l}\frac{1}{\alpha} \\
\frac{1}{0} \\
3\end{array}$} & & 70 & 70 & 67 & 65 & 70 & 75 & 75 & 70 & 65 \\
\hline & Engine control room & & & & & & & & & \\
\hline & Workshops & - & 85 & 80 & 80 & - & 85 & 80 & 80 & 80 \\
\hline & Open deck working areas & 70 & & 75 & - & - & 63 & - & - & 63 \\
\hline & Laundries & - & - & - & 75 & - & - & - & - & 75 \\
\hline & Continuously Manned Machinery Spaces & - & - & - & 85 & - & 90 & 90 & - & 85 \\
\hline & $\begin{array}{l}\text { Not Continuously Manned Machinery } \\
\text { Spaces }\end{array}$ & - & - & 110 & 108 & - & 110 & 110 & 105 & 105 \\
\hline & $\begin{array}{l}\text { Cargo Handling Spaces/Areas Near Cargo } \\
\text { Handling Equipment }\end{array}$ & - & - & - & 80 & - & - & - & - & 80 \\
\hline
\end{tabular}


Fan Rooms

Alleyways, changing rooms

Listing posts, Bridge wings

Galleys

Pantries

Stores

Wheelhouse

\begin{tabular}{lcccccccc}
- & - & - & 85 & - & - & - & - & $\mathbf{8 5}$ \\
- & - & - & - & - & 70 & - & - & $\mathbf{7 0}$ \\
- & - & 65 & - & - & - & 70 & 70 & $\mathbf{6 5}$ \\
- & 70 & 68 & 70 & - & 75 & - & 70 & $\mathbf{6 8}$ \\
- & - & 66 & 70 & - & - & - & - & $\mathbf{6 6}$ \\
- & - & 80 & 70 & - & - & - & - & $\mathbf{7 0}$ \\
- & - & - & 55 & 60 & 85 & - & 65 & $\mathbf{5 5}$ \\
\hline
\end{tabular}

Table 5: Proposed preliminary noise limits for passenger compartments

\begin{tabular}{llllllll}
\hline & & \multicolumn{6}{c}{ Noise Level, dB(A) } \\
Locations & ABS & BV & DNV & GL & LR & RINA & PROPOSED \\
\hline Passenger top level cabins & 45 & 45 & 44 & 44 & 45 & 45 & $\mathbf{4 4}$ \\
Passenger standard cabins & 45 & 49 & 49 & 46 & 49 & 50 & $\mathbf{4 5}$ \\
Outside installation & 65 & 65 & 65 & 64 & 67 & 65 & $\mathbf{6 4}$ \\
Discotheque, ballroom & 60 & 65 & 55 & 52 & 55 & 55 & $\mathbf{5 2}$ \\
Restaurant, lounge & 55 & 55 & 55 & 52 & 55 & 55 & $\mathbf{5 2}$ \\
Libraries, theatre & 55 & 53 & 55 & 52 & 50 & 52 & $\mathbf{5 0}$ \\
Shops & 55 & 60 & 55 & 52 & 60 & 55 & $\mathbf{5 2}$ \\
Gymnasium & 65 & 60 & 55 & 52 & 55 & 55 & $\mathbf{5 2}$ \\
Corridors, staircase & 60 & 60 & 55 & 54 & 55 & 60 & $\mathbf{5 4}$ \\
Hospital & 45 & 55 & 55 & 54 & 52 & 50 & $\mathbf{4 5}$ \\
\hline
\end{tabular}

Table 6: Dependent variable in models. Numbers only refer to specific items used in the questionnaires

deployed in the SILENV Project, and are of no particular value here.

\begin{tabular}{ll}
\hline & Models \& Dependent variables \\
\hline Comfort & N2c - Annoyance \\
& O1c - Overall feeling of discomfort \\
& N2p - Annoyance \\
Performance & O1p - Quality impairment \\
& Overall feeling of wellbeing \\
\hline
\end{tabular}

Table 7: Noise limits per human response

\begin{tabular}{lll}
\hline Extra probability relative to base line & Noise Annoyance, $\mathrm{dB}(\mathrm{A})$ & Noise Induced Work Quality Impairment, $\mathrm{dB}(\mathrm{A})$ \\
\hline $5 \%$ & 48 & 55 \\
$10 \%$ & 55 & 64 \\
$15 \%$ & 60 & 71 \\
$20 \%$ & 65 & 77 \\
$25 \%$ & 70 & 82 \\
$30 \%$ & 75 & 86 \\
\hline
\end{tabular}

Table 8: Percentages of vessels which comply with given noise levels (SILENV, 2012) for the different locations and corresponding location types as defined in Table 10.

\begin{tabular}{|c|c|c|c|c|c|c|c|c|c|c|c|c|c|}
\hline \multirow[b]{2}{*}{ Locations } & \multirow{2}{*}{$\begin{array}{l}\text { Correspo } \\
\text { nding } \\
\text { location } \\
\text { type }\end{array}$} & \multicolumn{2}{|c|}{$x=50 \%$} & \multicolumn{2}{|c|}{$x=40 \%$} & \multicolumn{2}{|c|}{$x=30 \%$} & \multicolumn{2}{|c|}{$\mathrm{x}=\mathbf{2 0} \%$} & \multicolumn{2}{|c|}{$\mathrm{x}=10 \%$} & \multicolumn{2}{|c|}{$x=5 \%$} \\
\hline & & $\begin{array}{l}\text { Noise } \\
\text { limit } \\
d B(A)\end{array}$ & $\begin{array}{l}\text { Exact } \\
\text { percen } \\
\text { t. } \%\end{array}$ & $\begin{array}{l}\text { Noise } \\
\text { limit } \\
\mathrm{dB}(\mathrm{A})\end{array}$ & $\begin{array}{l}\text { Exact } \\
\text { percen } \\
\text { t. } \%\end{array}$ & $\begin{array}{l}\text { Noise } \\
\text { limit } \\
\mathrm{dB}(\mathrm{A})\end{array}$ & $\begin{array}{l}\text { Exact } \\
\text { percen } \\
\text { t. } \%\end{array}$ & $\begin{array}{l}\text { Noise } \\
\text { limit } \\
\text { dB(A) }\end{array}$ & $\begin{array}{l}\text { Exact } \\
\text { perce } \\
\text { nt. \% }\end{array}$ & $\begin{array}{l}\text { Noise } \\
\text { limit } \\
\mathrm{dB}(\mathrm{A})\end{array}$ & $\begin{array}{l}\text { Exact } \\
\text { percen } \\
\text { t. } \%\end{array}$ & $\begin{array}{l}\text { Noise } \\
\text { limit } \\
\mathrm{dB}(\mathrm{A})\end{array}$ & $\begin{array}{l}\text { Exact } \\
\text { percen } \\
\text { t. } \%\end{array}$ \\
\hline Passenger & 1 & 54 & 46 & 54 & 39 & 51 & 31 & 50 & 27 & 46 & 12 & 44 & 4 \\
\hline
\end{tabular}




\section{Cabin}

\begin{tabular}{|c|c|c|c|c|c|c|c|c|c|c|c|c|}
\hline Crew Cabin & 1 & 60 & 52 & 59 & 41 & 57 & 33 & 54 & 19 & 51 & 11 & 49 \\
\hline Offices & 2 & 59 & 49 & 58 & 42 & 55 & 32 & 52 & 25 & 51 & 14 & 49 \\
\hline Public Spaces & 3 & 60 & 52 & 59 & 44 & 57 & 32 & 56 & 24 & 55 & 12 & 52 \\
\hline $\begin{array}{l}\text { Crew Public } \\
\text { Spaces }\end{array}$ & 4 & 66 & 49 & 65 & 42 & 63 & 34 & 60 & 20 & 53 & 10 & 50 \\
\hline Outdoor Areas & 6 & 76 & 47 & 76 & 40 & 74 & 27 & 69 & 20 & 59 & 13 & 59 \\
\hline Wheelhouse & 7 & 62 & 54 & 61 & 42 & 58 & 31 & 57 & 23 & 55 & 12 & 54 \\
\hline Work Spaces & 9 & 83 & 53 & 82 & 40 & 79 & 31 & 76 & 18 & 73 & 10 & 69 \\
\hline Control Room & 8 & 70 & 51 & 69 & 40 & 66 & 30 & 62 & 23 & 60 & 11 & 58 \\
\hline $\begin{array}{l}\text { Auxiliary } \\
\text { Engine Room }\end{array}$ & 11 & 105 & 46 & 104 & 39 & 102 & 23 & 97 & 15 & 89 & 8 & 79 \\
\hline Engine Room & 11 & 108 & 50 & 107 & 40 & 106 & 27 & 105 & 21 & 102 & 10 & 101 \\
\hline
\end{tabular}

Table 9: Locations used for the SILENV Green Noise Label

\begin{tabular}{|c|c|c|c|}
\hline Location Type & Group Name & Location Example & Noise Limits, $\mathrm{dB}(\mathrm{A})$ \\
\hline \multirow[t]{3}{*}{1} & \multirow[t]{3}{*}{ Cabins } & Passenger Cabins & 50 \\
\hline & & Crew Cabins & 50 \\
\hline & & Hospital & 50 \\
\hline 2 & Offices & Offices & 53 \\
\hline \multirow[t]{2}{*}{3} & \multirow[t]{2}{*}{ Public Spaces A } & Libraries & 55 \\
\hline & & Calm Public Spaces & 55 \\
\hline \multirow[t]{4}{*}{4} & \multirow[t]{4}{*}{ Public Spaces B } & Restaurant & 60 \\
\hline & & Lounge & 60 \\
\hline & & Mess room & 60 \\
\hline & & Shops & 60 \\
\hline \multirow[t]{4}{*}{5} & \multirow[t]{4}{*}{ Public Spaces C } & Discotheque, dance floor & 65 \\
\hline & & Ball room & 65 \\
\hline & & Corridor & 65 \\
\hline & & Staircase & 65 \\
\hline \multirow[t]{2}{*}{6} & \multirow[t]{2}{*}{ Outdoor Areas } & Open recreational areas & 70 \\
\hline & & Bridge wings / Open deck working areas & 70 \\
\hline \multirow[t]{2}{*}{7} & \multirow[t]{2}{*}{ Wheelhouse } & Wheelhouse & 60 \\
\hline & & Radio Room & 60 \\
\hline \multirow[t]{2}{*}{8} & \multirow[t]{2}{*}{ Work space A } & Engine Control Room & 65 \\
\hline & & Galleys & 65 \\
\hline \multirow[t]{5}{*}{9} & \multirow[t]{5}{*}{ Work space B } & Pantries & 75 \\
\hline & & Stores & 75 \\
\hline & & Laundries & 75 \\
\hline & & Workshops & 75 \\
\hline & & Garage & 75 \\
\hline 10 & Work space $\mathrm{C}$ & Continuously manned machinery space & 90 \\
\hline 11 & Work space D & Not Continuously manned machinery space & 105 \\
\hline
\end{tabular}

